\title{
Cutaneous Manifestations of Infective Endocarditis
}

\section{Serena Di Marino ${ }^{1}$, Francesca Cortese ${ }^{2}$}

1. Unit of Cardiology, "Valle D'Itria" Hospital, Martina Franca, Italy

2. Unit of Cardiology, "Giovanni Paolo II" Hospital, Policoro, Italy

\section{Corresponding author:}

Francesca Cortese,

Unit of Cardiology,

Giovanni Paolo II" Hospital,

Policoro, Italy

Email: francescacortese@hotmail.it

\section{Highlights}

Despite advances in diagnosis and treatment, infective endocarditis still shows considerable morbidity and mortality rates. The dermatological examination in patients with suspected infective endocarditis may prove very useful, as it might reveal suggestive abnormalities of this disease, such as Osler's nodes and Janeway lesions. These cutaneous manifestations of infective endocarditis are currently found only in about $20 \%$ of endocarditis cases, their presence, expression of an immune-mediated response and septic microembolism is associated to with poor outcome. We report a case of a woman with infective endocarditis and the typical cutaneous manifestations

Keywords: $\quad$ cutaneous manifestations; infective endocarditis; systemic embolization.

Citation: Di Marino S, Cortese F. Cutaneous Manifestations of Infective Endocarditis. International Cardiovascular Forum Journal 2020;21:33-34.DOI: 10.17987/icfj.v21i0.713.

A 47-year-old woman with a history of intravenous drug use, came to our observations for fever for a few days.

The arterial blood pressure and the heart rate were in normal range. The physical examination showed the presence of cutaneous lesions in the nail beds and palms that were typical for splinter hemorrhages associated with endocarditis, painful lesions consistent with Osler nodes and painless Janeway lesions, figu e.

The cardiac examination revealed a diastolic murmur grade III/ IV near the heart's base. The laboratory biomarkers showed the elevation of C-reactive protein, erythrocyte sedimentation rate and procalcitonin, leucocytosis. and an increase in the indices of hepatocyte necrosis.

The echocardiographic evaluation showed the presence of an endocarditis vegetation on the left cusp of the aortic valve determining a severe regurgitation.

The subject had a staphylococcus aureus endocarditis. She underwent aortic valve replacement with biological prosthesis, see panel $D$, intra-operatory view.
Cutaneous manifestations of infective endocarditis, very common in the pre-antibiotic era, are currently found only in about $20 \%$ of endocarditis cases [1].

Osler's nodes are typically painful lesions that occur on fingers and toes and are attributed to an immune-mediated response. In contrast, splinter hemorrhages (involving the distal nail bed) and Janeway lesions (involving the palms and soles) are painless and secondary to septic microembolism.

Osler's nodes are painful, purple nodular lesions, usually found on the tips of fingers and toes. Janeway lesions, in turn, are painless erythematous macules that usually affect palms and soles [2].

Early recognition of these clinical signs is important as they indicate the presence of systemic embolization and are associated with poor outcomes [3].

\section{Declarations of interest}

The authors declare no conflicts of inte est.

\section{Acknowledgements}

The authors state that they abide by the "Requirements for Ethical Publishing in Biomedical Journals" [4]. 


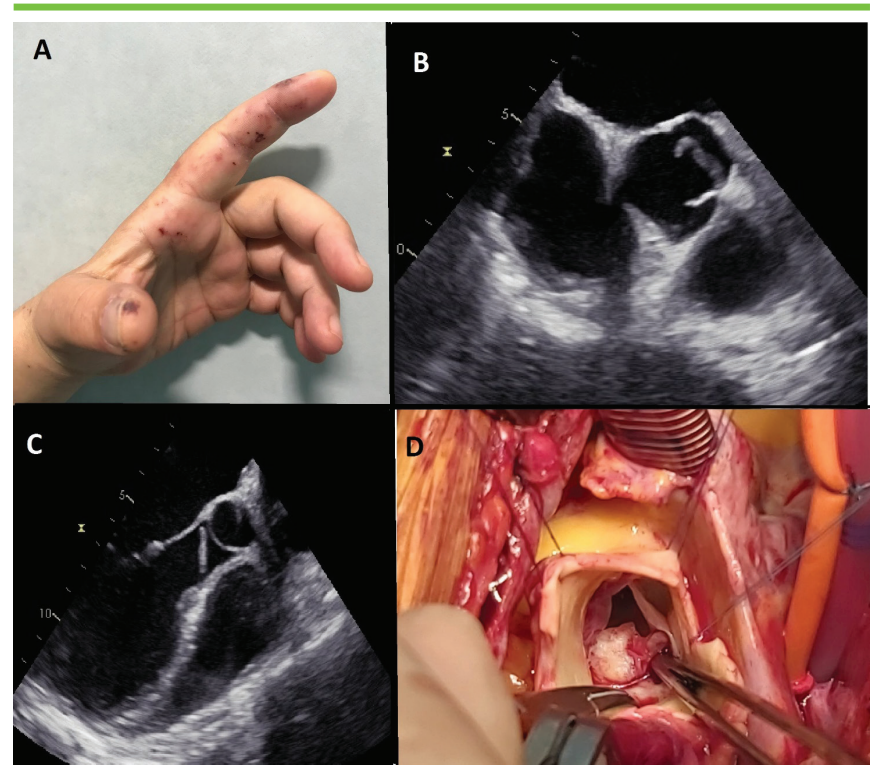

Figure 1. Cutaneous manifestations of a staphylococcus endocarditis of the left aortic cusp.

Panel A: cutaneous lesions in the nail beds and palms that were typical for splinter hemorrhages associated with endocarditis (black circle), painful lesions consistent with Osler nodes (black arrow) and painless Janeway lesions (white arrow), figu e.

Panel B and C: trans-esophageal echocardiographic examination showing the endocarditis vegetation on the left aortic cusp (white arrow).

Panel D: intra-operatory view, the endocarditis vegetation is well evident on the aortic cusp.

\section{References.}

1. Murdoch DR, Corey GR, Hoen B, Miró JM, Fowler VG, Bayer AS, Karchmer AW, Olaison L, Pappas PA, Moreillon P, Chambers ST, Chu VH, Falcó V, Holland DJ, Jones P, Klein JL, Raymond NJ, Read KM, Tripodi MF, Utili R, MD, Wang A, Woods CW, Cabell CH, and The ICE Investigators. Clinical Presentation, Etiology and Outcome of Infective Endocarditis in the 21st Century: The International Collaboration on Endocarditis-Prospective Cohort Study. Arch Intern Med. 2009 Mar 9;169(5):463-73. DOI: 10.1001/ archinternmed.2008.603.

2. Silverman ME, Upshaw $\mathrm{CB}$., Jr Extracardiac manifestations of infective endocarditis and their historical descriptions. Am J Cardiol. 2007;100(12):1802-7. DOI: 10.1016/j.amjcard.2007.07.034.

3. Servy A, Valeyrie-Allanore L, Alla F, Lechiche C, Nazeyrollas P, Chidiac C, Hoen B, Chosidow O, Duval X. Association Pour l'Etude et la Prévention de l'Endocardite Infectieuse Study Group. Prognostic value of skin manifestations of infective endocarditis. JAMA Dermatol. DOI: 10.1001/ jamadermatol.2013.8727

4. Shewan LG, Coats AJS, Henein MY. Authors' Responsibilities and Ethical Publishing. International Cardiovascular Forum Journal 2018;13:3-4. DOI: 10.17987/icfj.v13i0.525 